\title{
Research on Dynamic Modeling and Application of Kinetic Contact Interface in Machine Tool
}

\author{
Dan $X u^{1,2}$ and Zhixin Feng ${ }^{1,2}$ \\ ${ }^{1}$ School of Reliability and Systems Engineering, Beihang University, Beijing 100191, China \\ ${ }^{2}$ Science \& Technology on Reliability \& Environmental Engineering Laboratory, Beihang University, Beijing 100191, China
}

Correspondence should be addressed to Dan Xu; xudan@buaa.edu.cn

Received 22 July 2016; Accepted 16 October 2016

Academic Editor: A. El Sinawi

Copyright (c) 2016 D. Xu and Z. Feng. This is an open access article distributed under the Creative Commons Attribution License, which permits unrestricted use, distribution, and reproduction in any medium, provided the original work is properly cited.

A method is presented which is a kind of combining theoretic analysis and experiment to obtain the equivalent dynamic parameters of linear guideway through four steps in detail. From statics analysis, vibration model analysis, dynamic experiment, and parameter identification, the dynamic modeling of linear guideway is synthetically studied. Based on contact mechanics and elastic mechanics, the mathematic vibration model and the expressions of basic mode frequency are deduced. Then, equivalent stiffness and damping of guideway are obtained in virtue of single-freedom-degree mode fitting method. Moreover, the investigation above is applied in a certain gantry-type machining center; and through comparing with simulation model and experiment results, both availability and correctness are validated.

\section{Introduction}

The dynamic analysis and simulation technology of numerical control machine tool are a very important research direction in modern advanced manufacturing technology and equipment technology. In a numerical control machine tool, the linear rolling guide is not only a significant functional component but also an important kinetic contact interface, meaning its characteristic has a direct effect on the machining precision and performance. Therefore, the modeling of contact interface, which takes the dynamic property of the $\mathrm{NC}$ machine tool into consideration, is a prerequisite research for establishing the dynamic overall model. Without this, it is impossible to get a practical conclusion.

For the dynamic analysis and prediction of machine tool, the modeling of contact interface and accurate identifying of the parameters are the main difficulty. In recent years, the domestic and overseas research of contact interface is basic on three aspects: the mechanism of contact interface, modeling, and parameter identification. Some of the researchers, who are represented by Wen et al. [1,2], put forward the scaleindependent stiffness fractal modeling of the normal and tangential contact. At the same time, they reveal the nonlinear relationship between the contact stiffness and each interface parameter. The researchers, represented by Zhang et al. [3] and Mao et al. [4], build the fundamental property model of contact interface and multinode dynamic model; Dhupia et al. [5] applies the frequency-domain joint part model with weak nonlinear characteristic to the basic machine tool modeling and predicts the processing performance. When it comes to identifying the parameter of the joint part, there are several main ways such as frequency response function identification method [6], response coupling method [7], and contact interface parameter optimization method which is based on finite element modeling [8]. At present, the research of joint part is in the contending stage, and there are numerous problems of the mechanism and modeling to be solved.

There are certain difficulties to apply the mechanism model to engineering, because although the fundamental performance model and parameter statistic obtained have a versatility, it should be based on a great amount of experiments.

On the basis of the researches before [9-11] and starting from the material and structure aspects, this paper puts forward a combined "analysis-experiment" dynamic modeling method for linear guideway and studies the method of identifying the parameters of guideway contact interface. Furthermore, this paper builds a four-in-one joint part 
research method of "static stiffness model-vibration modelexperimental parameter-parameter identification" and applies this method to the guideway contact part and overall dynamic modeling of the gantry machining center. The research results provide an effective and feasible solution channel and practical method to predict the machine performance in the pattern design phase.

\section{Modeling of the Rolling Guideway Contact Part}

2.1. Modeling Method. From the perspective of material parameters and structural distortion and based on the elastic mechanics and vibration mechanics theory, the guideway contact part dynamic modeling method is established from these four aspects, "static stiffness model, vibration model, experimental parameter, and parameter identification.” Figure 1 clearly shows the relationship of each part of the method and the parameter that should be provided for next part. First of all, obtain the relationship between the stress and deformation through analyzing the static dynamics while the rolling linear guideway is under the general loading, solve the static stiffness via building the guideway static stiffness model, and provide the input parameter for the guideway vibration model. Secondly, employ the Lagrange method to analyze the vibration property of the linear rolling guideway and solve the basic modal vibration frequency of the vibration model through using analytic method, to provide the input requirement for the dynamic model parameter identification. At last, with the help of the hammer-hitting experiment, the multipoint frequency response function of the guideway is acquired. Combined with the guideway vibration basic modal frequency, the single degree modal fitting method is used to obtain the stiffness and damping value of the guideway equivalent model.

2.2. Static Stiffness Model. In the condition that the linear rolling guideway is under the load in vertical direction $F_{V}$, the load in horizontal direction $F_{H}$, and vertical moment $M_{\gamma}$ (rotating around the $y$ axis) (shown in Figure 2), the relation [12] between the stress and deformation is obtained via the mechanical analysis while the linear guideway is under general loading. The equation system is presented as

$$
\begin{gathered}
F_{V}=f_{1}\left(\delta_{V}, \delta_{H}, \gamma\right), \\
F_{H}=f_{2}\left(\delta_{V}, \delta_{H}, \gamma\right), \\
M_{\gamma}=f_{1}\left(\delta_{V}, \delta_{H}, \gamma\right) .
\end{gathered}
$$

This nonlinear equation system can be solved by numerical computation method.

Substitute a series of different external applied load $F_{V}$, $F_{H}$, and $M_{\gamma}$ into the algorithm above and then a series of relative displacement $\delta_{V}, \delta_{H}$, and $\gamma$ under different loading of the guideway can be obtained. Using the computer calculating method, the vertical direction stiffness, horizontal direction
TABLE 1: MRB35 rolling guideway model parameters.

\begin{tabular}{lc}
\hline Parameter Items & Values \\
\hline The length of the slider $L_{6}$ & $103 \mathrm{~mm}$ \\
The diameter of the roller $\mathrm{Da}$ & $4.5 \mathrm{~mm}$ \\
The length of the roller $L$ & $5.1 \mathrm{~mm}$ \\
The mass of the slider $M$ & $2.2 \mathrm{~kg}$ \\
The moment of inertia around $x$-axis of & $3.927626 \times 10^{-3} \mathrm{~kg} \mathrm{~m}^{2}$ \\
the slider $J_{x}$ & \\
$\begin{array}{l}\text { The moment of inertia around } y \text {-axis of } \\
\text { the slider } J_{y}\end{array}$ & $5.761594 \times 10^{-3} \mathrm{~kg} \mathrm{~m}^{2}$ \\
$\begin{array}{l}\text { The moment of inertia around } z \text {-axis of } \\
\text { the slider } J_{z}\end{array}$ & $2.467506 \times 10^{-3} \mathrm{~kg} \mathrm{~m}^{2}$ \\
The number of the rollers $Z_{L}$ & 21 \\
The horizontal distance between each \\
roller $e$ \\
$\begin{array}{l}\text { The vertical distance between loaded } \\
\text { point and upper rollers } h_{1}\end{array}$ \\
$\begin{array}{l}\text { The vertical distance between each } \\
\text { roller } h_{0} \\
\text { Tight deformation amount } \Delta \\
\text { Contact angle } \beta\end{array}$ \\
\hline
\end{tabular}

stiffness, and the rotation angular rigidity can be, respectively, solved:

$$
\begin{gathered}
K_{V}=\left.\frac{\partial F_{V}}{\partial \delta_{V}}\right|_{F_{V}}, \\
K_{H}=\left.\frac{\partial F_{H}}{\partial \delta_{H}}\right|_{F_{H}}, \\
K_{\gamma}=\left.\frac{\partial M_{\gamma}}{\partial_{\gamma}}\right|_{M_{\gamma}} .
\end{gathered}
$$

On the basis of the computing method above and MATLAB software, taking the Schneeberger MRB35 linear rolling guideway as an example, the parameters of the guideway measure are shown in Table 1.

Figure 3 shows the relation between the vertical bearing load and vertical direction deformation while the load is within the bearing capacity. In Figure 3, the line marked with red five-pointed stars represents computing data by theoretical model, and the line marked with blue points represents the experimental data provided by the guideway manufacturer. As is shown in the figure, the relation between the loading and deformation is moderate linear and it can be approximately treated as a linear relation. In the simplified model, it can be replaced by a linear model.

2.3. Dynamic Model. Ignoring the mass of the roller, linear rolling guideway vibration model only takes the normal direction stiffness of the roller (the normal direction means the direction that is vertical to the contact interface) and simplifies the roller between the two contact interfaces as a spring that is vertical to the contact interface, whose stiffness is $K_{n}$. It is shown in Figure 4. 


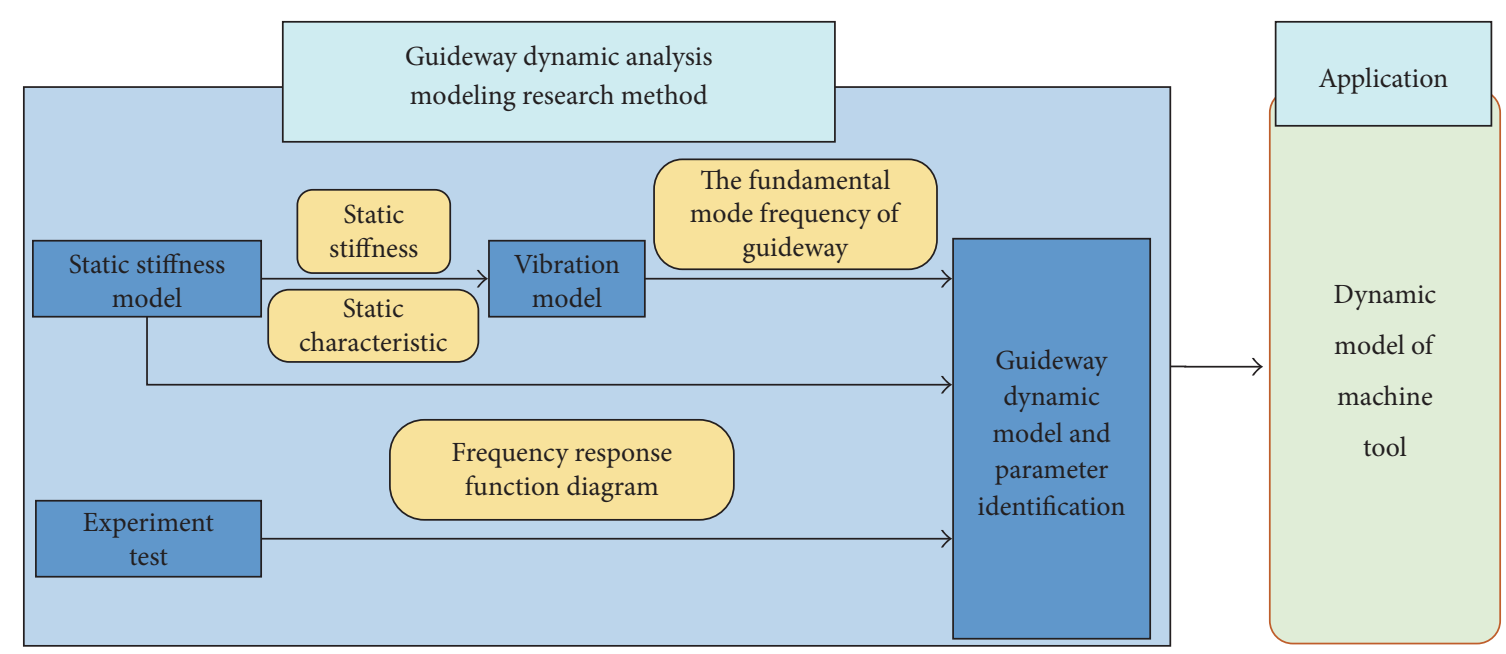

FIgURE 1: Mind map of the guideway dynamic model research method.
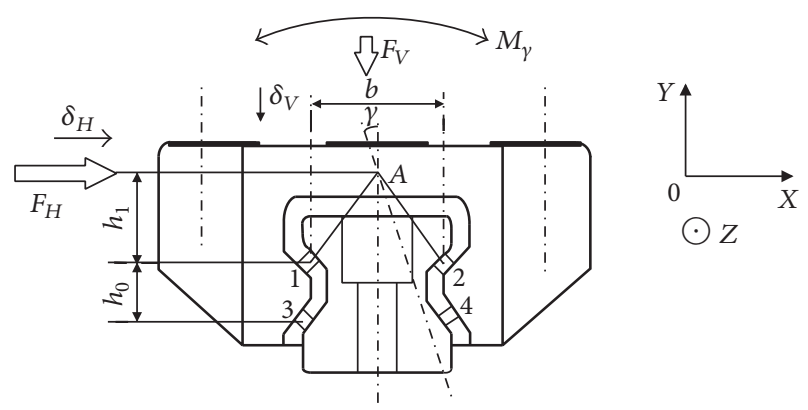

$\odot Z$

FIgURE 2: Bearing loading and guideway deformation graph.

The solution for the stiffness $K_{n}[9,10]$ is as follows.

The simplified spring normal stiffness of the single sphere roller is

$$
K_{n}=\frac{d F}{d \alpha}=\frac{3}{2} k_{h} \alpha^{1 / 2} .
$$

The simplified spring normal stiffness of the single cylinder roller is

$$
\begin{aligned}
K_{n} & =\frac{d Q}{d \delta}=\frac{10}{9} k_{l} L^{8 / 9} \delta^{1 / 9} \\
\text { or } K_{n} & =\frac{K_{V}}{4 Z \sin \beta},
\end{aligned}
$$

where $K_{n}$ means the spring normal stiffness which is simplified from the single roller; $k_{h}$ means the roller contact rigidity of the spherical guideway; $\alpha$ means the elastic deformation of the roll ball; $k_{l}$ means the roller contact stiffness of the roller guideway; $L$ means the length of the roller guideway; $\delta$ means the elastic deformation of the roller guideway; $K_{V}$ means the vertical stiffness of the linear guideway; $Z$ means the number of the single row roller; $\beta$ means the contact angle of guideway and groove.

Using the Lagrange equation, the dynamic equation of the linear guideway can be detected. Lagrange equation uses the

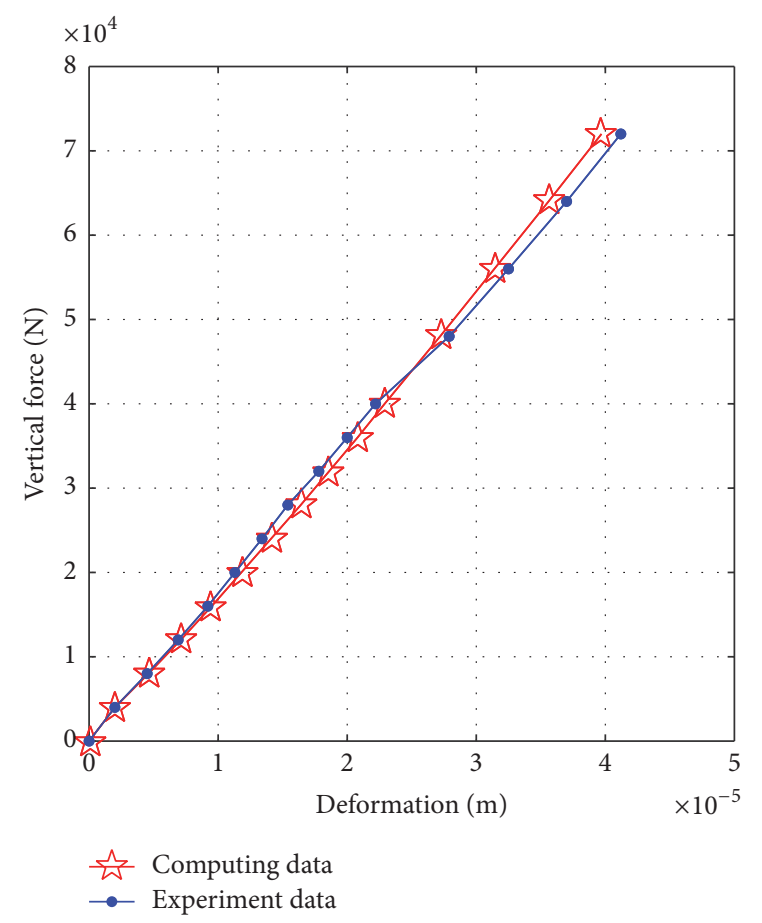

FIgURE 3: The relationship of vertical stress and deformation of MRB35 guideway.

variation of the generalized coordinates to present the virtual displacement of the particle in the particle system. This kind of system is more useful than Newton's laws of motion while solving some problems (e.g., the small oscillation theory and rigid body dynamics).

The Lagrange equation of linear rolling guideway is given in the following:

$$
\frac{d}{d t}\left(\frac{\partial T}{\partial \dot{q}_{j}}\right)-\left(\frac{\partial T}{\partial q_{j}}\right)=Q_{j} \quad(j=1,2, \ldots, k),
$$



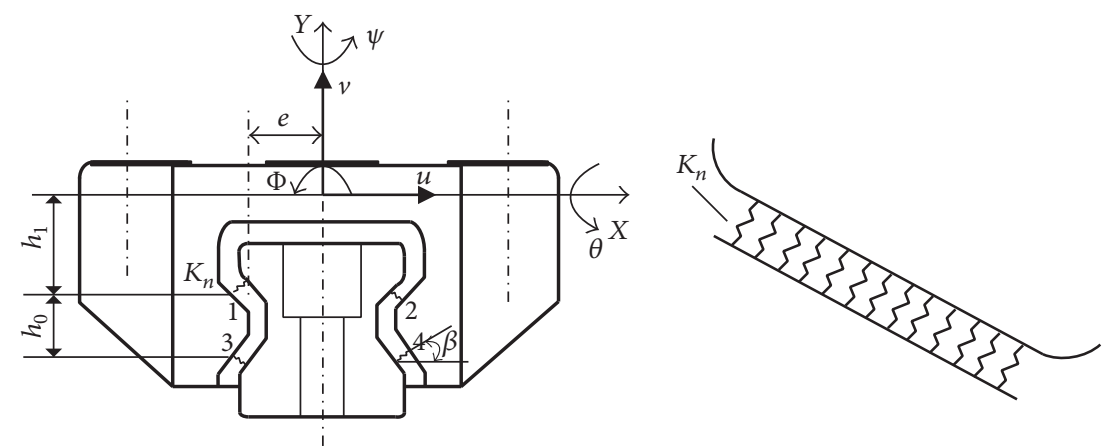

FIgURE 4: Simplified linear rolling guideway model.

where $T$ means the kinetic energy of the system; $q_{j}$ means the generalized coordinate of the system; $\dot{q}_{j}$ means the generalized velocity of the system; $Q_{j}$ means the generalized force which corresponds to the generalized coordinate of the system; $k$ means the number of the generalized coordinates of the system, meaning the free degree of the system.

If all the force applied on the particle is potential force, using $V$ to represent the potential function of the system; the generalized force corresponding to the generalized coordinate $q_{j}$ is

$$
Q_{j}=-\frac{\partial V}{\partial q_{j}}
$$

Defining $L=T-V, L$ is named the Lagrange function or dynamic potential. Then the Lagrange function in potential field can be written as

$$
\frac{d}{d t}\left(\frac{\partial L}{\partial \dot{q}_{j}}\right)-\left(\frac{\partial L}{\partial q_{j}}\right)=0 \quad(j=1,2, \ldots, k)
$$

The Lagrange function of the linear rolling guideway system shown in Figure 4 can be established directly. follows.

The overall dynamic energy $E_{k}$ can be expressed as

$$
E_{k}=\frac{1}{2} M \dot{u}^{2}+\frac{1}{2} M \dot{v}^{2}+\frac{1}{2} J_{x} \dot{\theta}^{2}+\frac{1}{2} J_{y} \dot{\psi}^{2}+\frac{1}{2} J_{z} \dot{\phi}^{2} .
$$

The potential function $E_{p}$ can be expressed as

$$
\begin{aligned}
E_{p} & =E_{p 1}=\frac{1}{2} K_{n} \sum_{i=1}^{Z_{L}}\left(\delta_{1 i}^{2}+\delta_{2 i}^{2}+\delta_{3 i}^{2}+\delta_{4 i}^{2}\right), \\
E_{p 1} & =\frac{1}{2} K_{n} \sum_{i=1}^{Z_{L}}\left[\left\{\left(u+h_{1} \phi+l_{1 i} \psi\right) \cos \beta\right.\right. \\
& \left.+\left(v-e \phi-l_{1 i} \theta\right) \sin \beta\right\}^{2}+\left\{\left(-u-h_{1} \phi-l_{2 i} \psi\right) \cos \beta\right.
\end{aligned}
$$

$$
\begin{aligned}
& \left.+\left(v+e \phi-l_{2 i} \theta\right) \sin \beta\right\}^{2}+\left\{\left(u+h_{3} \phi+l_{3 i} \psi\right) \cos \beta\right. \\
& \left.+\left(-v+e \phi+l_{3 i} \theta\right) \sin \beta\right\}^{2} \\
& +\left\{\left(-u-h_{3} \phi-l_{4 i} \psi\right) \cos \beta\right. \\
& \left.\left.+\left(-v-e \phi+l_{4 i} \theta\right) \sin \beta\right\}^{2}\right], \\
& Z_{L 1}=Z_{L 2}=Z_{L 3}=Z_{L 4}=Z_{L} \text {, } \\
& l_{1 i}=l_{2 i}=l_{3 i}=l_{4 i}=\left(\frac{Z_{L}-2 i+1}{2\left(Z_{L}-1\right)}\right) l_{L} \\
& \left(i=1,2, \ldots, Z_{L}\right), \\
& h_{3}=h_{1}+h_{0}
\end{aligned}
$$

where $u$ means the displacement in $X$ direction; $v$ means the displacement in $Y$ direction; $\theta$ means the angular displacement around $x$-axis (pitching motion); $\psi$ means the angular displacement around $y$-axis (yawing motion); $\phi$ means angular displacement around $z$-axis (rolling motion); $M$ means the mass of slider; $J_{x}$ means the moment of inertia around $x$-axis of the slider; $J_{y}$ means the moment of inertia around $x$-axis of the slider; $J_{z}$ means the moment of inertia around $y$-axis of the slider; $e$ means the moment of inertia around $z$-axis of the slider; $h_{1}$ means $Y$ direction distance from the center of roller 1 to the origin of coordinate; $h_{0}$ means $Y$ direction distance from the center of roller 1 to the center of roller 3 ; $\beta$ means the angle between the normal direction of the contact interface and the horizontal $X$ direction; $E_{p 1}$ means the elastic potential energy of the normal direction spring; $Z_{L j}(j=1,2,3,4)$ means the number of the rollers in the $i$ th raceway; $l_{j i}(j=1,2,3,4)$ means the $z$-axis coordinate of the $i$ th roller in $j$ th raceway as is shown in Figure 5; the angle between $Y^{\prime}$ axis and $y$-axis is $(\pi / 2-\beta) ; l_{L}$ means the length of single raceway roller.

Establishing the linear guideway system dynamic function,

$$
\begin{aligned}
& M \ddot{u}+4 Z_{L} K_{n} \cos ^{2} \beta u+2 Z_{L} K_{n}\left(h_{1}+h_{3}\right) \cos ^{2} \beta \phi=0, \\
& M \ddot{v}+4 Z_{L} K_{n} \sin ^{2} \beta v=0,
\end{aligned}
$$




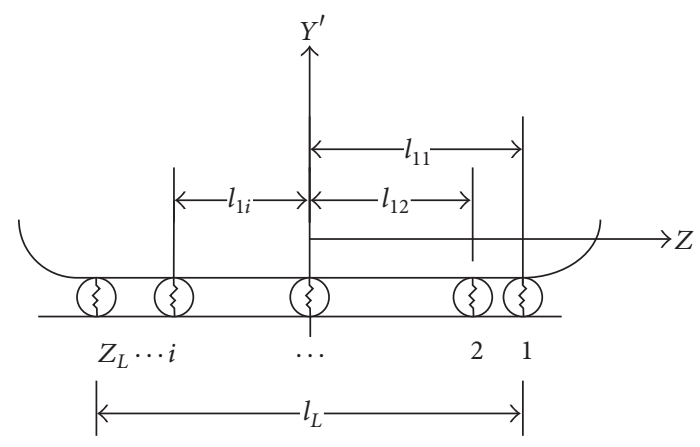

FIGURE 5: The position of the roller in $Y^{\prime} Z$ plane.

$$
\begin{aligned}
& J_{x} \ddot{\theta}+K_{n} \sum_{i=1}^{Z_{L}}\left(l_{1 i}^{2}+l_{2 i}^{2}+l_{3 i}^{2}+l_{4 i}^{2}\right) \sin ^{2} \beta \theta=0, \\
& J_{y} \ddot{\psi}+K_{n} \sum_{i=1}^{Z_{L}}\left(l_{1 i}^{2}+l_{2 i}^{2}+l_{3 i}^{2}+l_{4 i}^{2}\right) \cos ^{2} \beta \psi=0, \\
& J_{z} \ddot{\phi}+2 Z_{L} K_{n}\left(h_{1}+h_{3}\right) \cos ^{2} \beta u \\
& +\left\{2 Z_{L} K_{n}\left(h_{1}^{2}+h_{3}^{2}\right) \cos ^{2} \beta+4 Z_{L} K_{n} e^{2} \sin ^{2} \beta\right. \\
& \left.+4 Z_{L} K_{n} h_{0} e \sin \beta \cos \beta\right\} \phi=0 .
\end{aligned}
$$

Detected from (11) the vibration frequency of the direction that vertical to $y$-axis of the guideway can be obtained:

$$
f_{V}=\frac{1}{\pi} \sqrt{\frac{Z_{L} K_{n} \sin ^{2} \beta}{M}} .
$$

Detected from (12), the vibration frequency of the pitching motion around $x$-axis of the guideway can be obtained:

$$
f_{X P}=\frac{1}{2 \pi} \sqrt{\frac{K_{n} \sum_{i=1}^{Z_{L}}\left(l_{1 i}^{2}+l_{2 i}^{2}+l_{3 i}^{2}+l_{4 i}^{2}\right) \sin ^{2} \beta}{J_{x}}} .
$$

Detected from (4), the vibration frequency of the yawing motion around $y$-axis of the guideway can be obtained:

$$
f_{Y Y}=\frac{1}{2 \pi} \sqrt{\frac{K_{n} \sum_{i=1}^{Z_{L}}\left(l_{1 i}^{2}+l_{2 i}^{2}+l_{3 i}^{2}+l_{4 i}^{2}\right) \cos ^{2} \beta}{J_{y}}} .
$$

The displacement along $X$ direction $u$ and the angular displacement around $z$-axis couple together so (10) and (14) are simultaneously solved to get the vibration frequency.

$$
\begin{aligned}
& M \ddot{u}+4 Z_{L} K_{n} \cos ^{2} \beta u+2 Z_{L} K_{n}\left(h_{1}+h_{3}\right) \cos ^{2} \beta \phi=0, \\
& J_{z} \ddot{\phi}+2 Z_{L} K_{n}\left(h_{1}+h_{3}\right) \cos ^{2} \beta u \\
& \quad+\left\{2 Z_{L} K_{n}\left(h_{1}^{2}+h_{3}^{2}\right) \cos ^{2} \beta+4 Z_{L} K_{n} e^{2} \sin ^{2} \beta\right. \\
& \left.\quad+4 Z_{L} K_{n} h_{0} e \sin \beta \cos \beta\right\} \phi=0 .
\end{aligned}
$$

Suppose $u=U e^{j \omega t}$ and $\phi=\Phi e^{j \omega t}$, while $\omega$ represents the frequency and $j=\sqrt{-1}$.

Then the simultaneous equation above can be written as follows.

$$
\left[\begin{array}{cc}
c_{1}-M \omega^{2} & c_{2} \\
c_{2} & c_{3}-J_{z} \omega^{2}
\end{array}\right]\left[\begin{array}{l}
U \\
\Phi
\end{array}\right]=0
$$

In this expression,

$$
\begin{aligned}
c_{1}= & 4 Z_{L} K_{n} \cos ^{2} \beta, \\
c_{2}= & 2 Z_{L} K_{n}\left(h_{1}+h_{3}\right) \cos ^{2} \beta, \\
c_{3}= & 2 Z_{L} K_{n}\left(h_{1}^{2}+h_{3}^{2}\right) \cos ^{2} \beta+4 Z_{L} K_{n} e^{2} \sin ^{2} \beta \\
& +4 Z_{L} K_{n} h_{0} e \sin \beta \cos \beta .
\end{aligned}
$$

Solve (19):

$$
M J_{z} \omega^{4}-\left(c_{3} M+c_{1} J_{z}\right) \omega^{2}+c_{1} c_{3}-c_{2}^{2}=0
$$

Therefore,

$$
\begin{aligned}
& \omega_{1,2}^{2} \\
& =\frac{c_{3} M+c_{1} J_{z} \mp \sqrt{\left(c_{3} M+c_{1} J_{z}\right)^{2}-4 M J_{z}\left(c_{1} c_{3}-c_{2}^{2}\right)}}{2 M J_{z}} .
\end{aligned}
$$

The displacement along $X$ direction $u$ and the angular displacement around $z$-axis couple together so we suppose that the frequency obtained is low order rolling frequency $f_{\mathrm{RL}}$ and high order rolling frequency $f_{\mathrm{RH}}$ :

$$
\begin{aligned}
& f_{\mathrm{RL}}=\frac{\omega_{1}}{2 \pi}, \\
& f_{\mathrm{RH}}=\frac{\omega_{2}}{2 \pi} .
\end{aligned}
$$

The solution of the vibration model above is the vibration frequency of the linear rolling guideway.

The parameters of the experimental guideway Schneeberger MRB35-V2 are displayed in Table 1. The result of the vertical moving frequency, which is computed by the analytical method from the vibration model, is $f_{V}=3529 \mathrm{~Hz}$.

\section{Dynamic Parameter Identification of Rolling Guideway}

Because the contact part of the guideway has multiple modes, which can be known from the hammer-hitting experiment, numbers of groups vertical and horizontal "spring-damper" can be used as simplified equivalent model of the guideway contact part. We make a use of the results of the vibration model above and combine them with experiment to identify the dynamic parameters of the equivalent model.

The experimental facility of the hammer-hitting test is shown in Figure 6. The main apparatuses are listed in the following: 


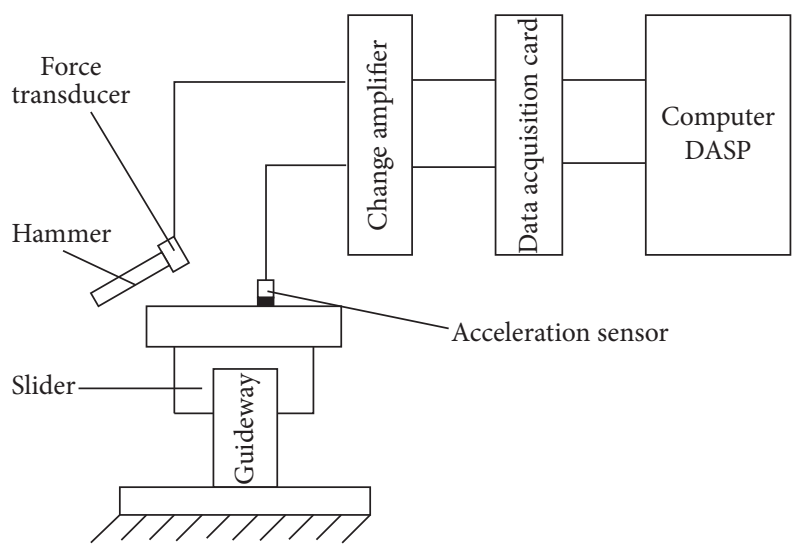

FIgURE 6: The schematic diagram of hammer-hitting experiment.

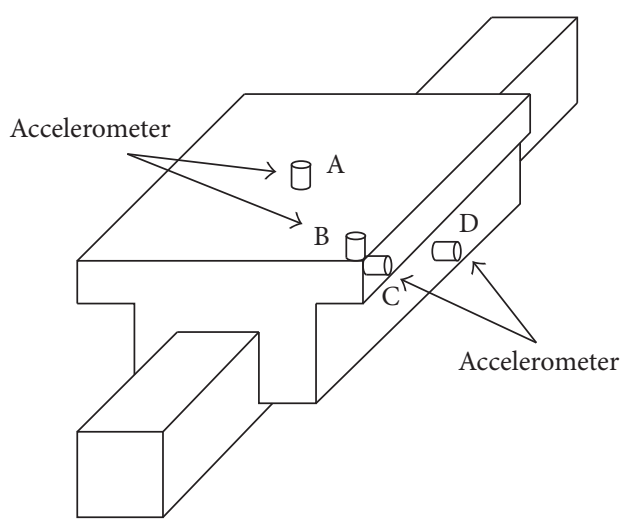

FIGURE 7: Measuring points map.

(i) MSC-1 Impact Hammer, $500 \mathrm{~kg}$ Force Transducer

(ii) YD 67D Miniature Accelerometer

(iii) DLF-3 Four-in-one Two-Channel Charge Amplifier

(iv) Four-Channel Data Collector with USB Interface INV306U, whose highest sampling frequency is $200 \mathrm{KHZ}$

The measure in the four points $\mathrm{A}, \mathrm{B}, \mathrm{C}$, and D is shown in Figure 7.

The vibration spectrums of the four points A, B, C, and $\mathrm{D}$ are displayed in Figure 8 (including the transfer function amplitude and correlation coefficient). The measured value of the vertical vibration frequency is $f_{V}=3450 \mathrm{~Hz}$, whose error is less than $3 \%$ compared with the theoretical calculation.

As is shown in Figure 8, the slider-roller-guideway is a system with multiple modes. Find out the necessary parameters by combining them with the analytical results of the theoretical vibration model, which is the vertical vibration frequency $f_{V}$ and horizontal vibration frequency $f_{H}$. And then identify the dynamic stiffness in both vertical and horizontal direction. The damping ratio and damping value are calculated by using the half-power method. The detail of the calculation is displayed in (24)-(29).
The stiffness in vertical direction is

$$
K_{V}=4 M \pi^{2} f_{V}^{2}
$$

The stiffness in horizontal direction is

$$
K_{H}=4 M \pi^{2} f_{H}^{2}
$$

The damping ratio in vertical direction is

$$
\xi_{V}=\frac{f_{V 2}-f_{V 1}}{2 f_{V}}
$$

The damping value in vertical direction is

$$
c_{V}=4 \pi M f_{V} \xi_{V} .
$$

The damping ratio in horizontal direction is

$$
\xi_{H}=\frac{f_{H 2}-f_{H 1}}{2 f_{H}} .
$$

The damping value in horizontal direction is

$$
c_{H}=4 \pi M f_{H} \xi_{H} .
$$

In these equations, $M$ represents the mass; $f_{V}$ represents the vertical direction vibration frequency; $f_{H}$ represents the horizontal direction vibration frequency; $f_{V 1}, f_{V 2}, f_{H 1}$, and $f_{H 2}$, respectively, represent the homologous half-power frequencies in vertical and horizontal directions.

The measured value of vibration frequency in vertical direction, which is detected from the experiment, is $f_{V}=$ $3450 \mathrm{~Hz}$ and the horizontal vibration frequency is $f_{H}=$ $1075 \mathrm{~Hz}$. The results can be computed by using (24)-(29).

Thus, the stiffness in vertical direction is

$$
K_{V}=1.03 \times 10^{9} \mathrm{~N} / \mathrm{m} .
$$

The damping value in vertical direction is

$$
c_{V}=2750 \mathrm{~N} \cdot \mathrm{s} / \mathrm{m} .
$$

The stiffness in horizontal direction is

$$
K_{H}=1.00 \times 10^{8} \mathrm{~N} / \mathrm{m} .
$$

The damping value in horizontal direction is

$$
c_{H}=3109 \mathrm{~N} \cdot \mathrm{s} / \mathrm{m} \text {. }
$$

\section{The Dynamic Analysis and Experimental Verification of Machine Tool Considering Contact Interface of Guideway}

4.1. The FEM Model of Machine Tool. We conduct the research on the gantry machining center driven by a linear electric motor (as is shown in Figure 9) and make use of the FEM software to analyze the dynamic property of the machining center. The guideway in the machine tool system, which is shown in Figure 10, is equivalent to the four-vertical-direction spring-damper system and eighthorizontal-direction spring-damper system. The dynamic parameters can be obtained by using the method mentioned above.

After adding the material property parameters, constraints, and loadings, we apply the modal analysis to the machining center and compute the first-six-order frequencies and modes of the overall machine tool (shown in Table 2). 
Amplitude and correlation — transfer function analysis—DASP
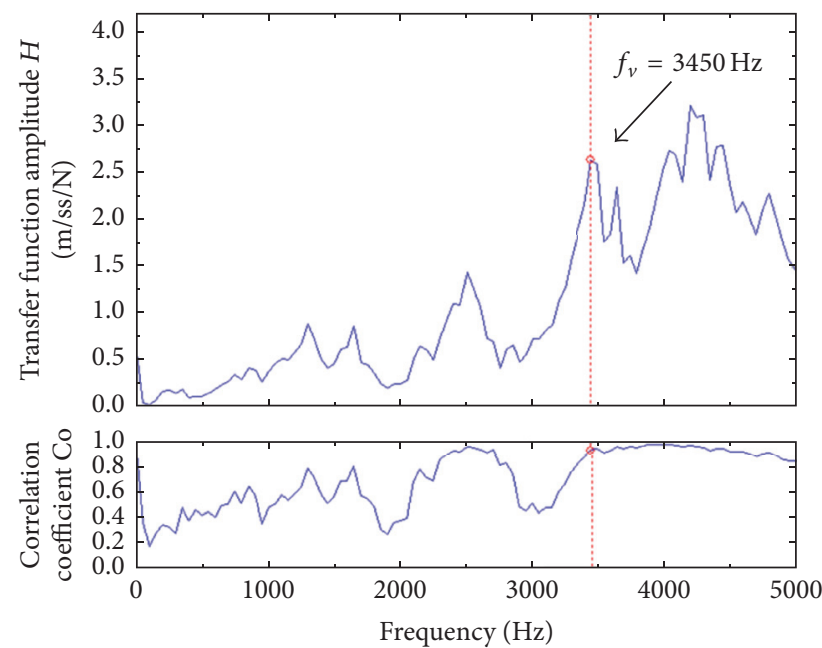

(a) Point $\mathrm{A}$
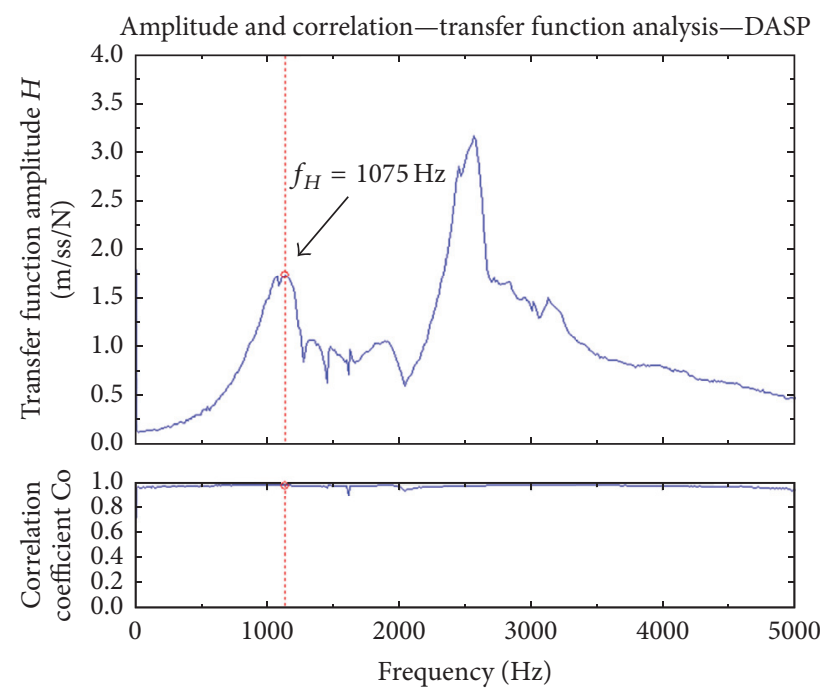

(c) Point C
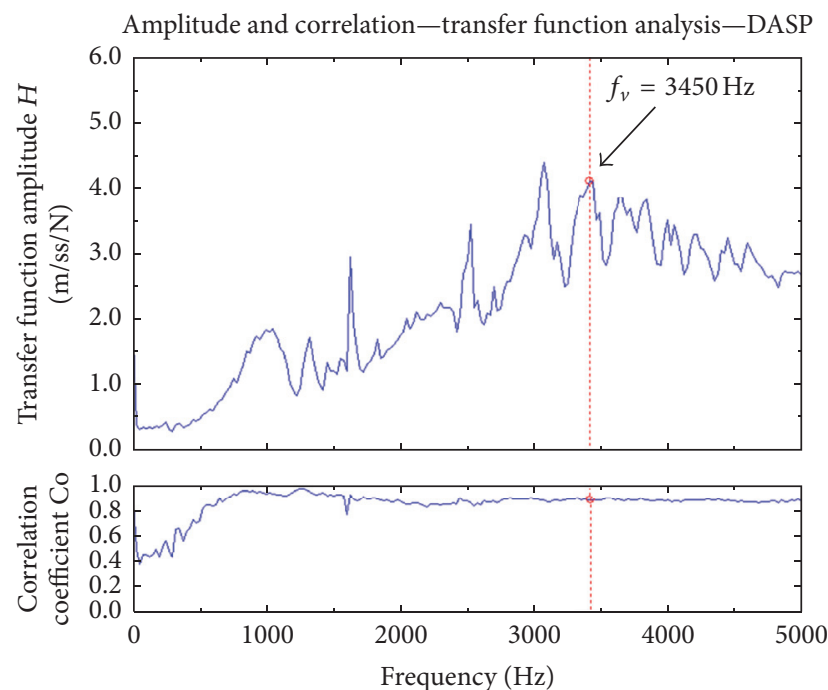

(b) Point B
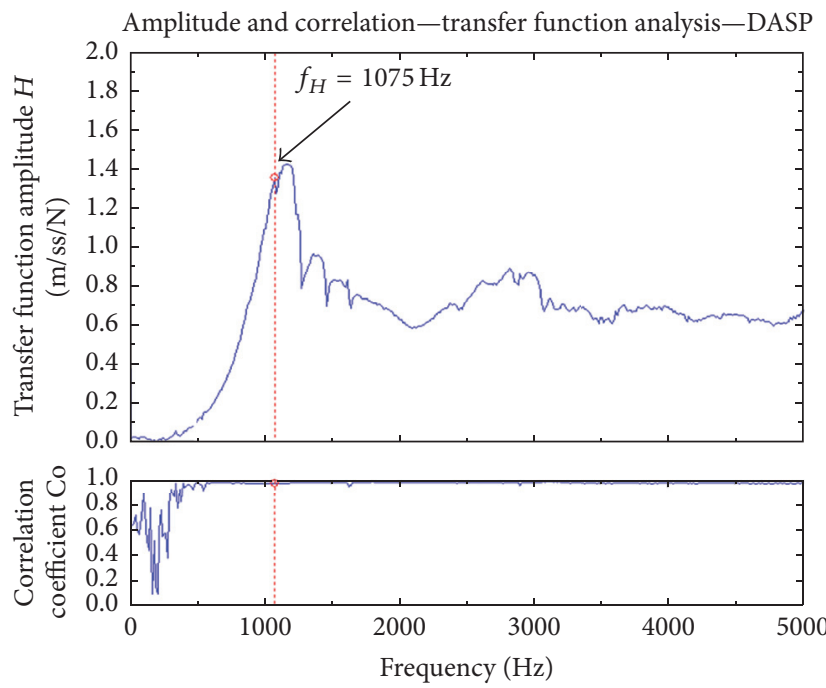

(d) Point D

FIGURE 8: The frequency response functional graph of acceleration-force of linear guideway.

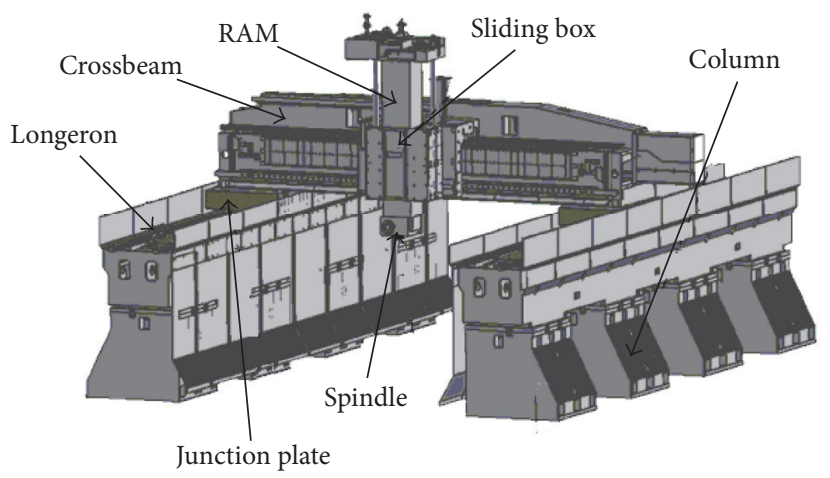

FIGURE 9: The model of gantry machining center. $x$-axis: the direction along the length of longeron, $y$-axis: the direction along the length of crossbeam, and $z$-axis: vertical direction.

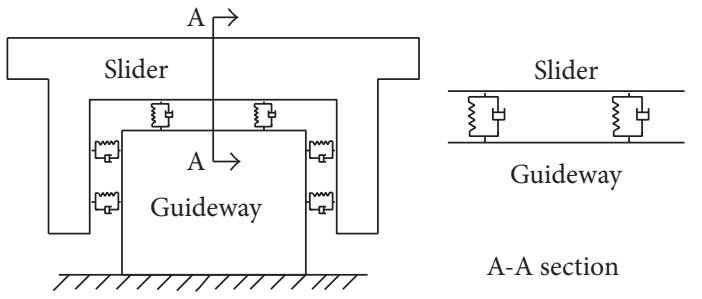

FIgURE 10: The dynamically equivalent model of the guideway.

4.2. The Overall Test. Using the hammer-hitting method, knock and pick up the signals, respectively, from these three directions $X, Y$, and $Z$. On account of the reason that the main consideration is the influence on the machine parts during 
TABLE 2: The first-six-order frequencies and modes of machine tool computed by FEM method.

\begin{tabular}{|c|c|c|c|}
\hline Order & $\begin{array}{l}\text { Frequency of } \\
\text { FEM model } \\
(\mathrm{Hz})\end{array}$ & Modes & Reasons \\
\hline 1 & 27.5 & $\begin{array}{c}\text { Crossbeam bends } \\
\text { around the horizontal } \\
\qquad Y \text { axis }\end{array}$ & $\begin{array}{l}\text { Junction plate and } \\
\text { longeron's guideway } \\
\text { pitching vibration }\end{array}$ \\
\hline 2 & 53.7 & $\begin{array}{l}\text { Crossbeam vibrating } \\
\text { up and down. Sliding } \\
\text { box bends around the } \\
\text { horizontal } Y \text { axis }\end{array}$ & $\begin{array}{l}\text { Crossbeam vibrates, } \\
\text { sliding box, and } \\
\text { crossbeam } \\
\text { guideway's rolling } \\
\text { vibration }\end{array}$ \\
\hline 3 & 55.1 & $\begin{array}{l}\text { Longeron and } \\
\text { crossbeam wagging }\end{array}$ & $\begin{array}{c}\text { Longeron's flexural } \\
\text { vibration }\end{array}$ \\
\hline 4 & 78.7 & $\begin{array}{l}\text { Junction Plate's small } \\
\text { amplitudes pitching } \\
\text { vibration. Sliding } \\
\text { box's guideway } \\
\text { pitching vibration }\end{array}$ & $\begin{array}{c}\text { Junction plate } \\
\text { guideway and } \\
\text { sliding box } \\
\text { guideway's pitching } \\
\text { vibration }\end{array}$ \\
\hline 5 & 83.0 & $\begin{array}{l}\text { Crossbeam bends } \\
\text { around } Z \text { axis. Sliding } \\
\text { box rolls around } Y \\
\text { axis }\end{array}$ & $\begin{array}{c}\text { Crossbeam's flexural } \\
\text { vibration }\end{array}$ \\
\hline 6 & 115.7 & $\begin{array}{l}\text { Crossbeam's pitching } \\
\text { vibration around } Y \\
\text { axis }\end{array}$ & $\begin{array}{c}\text { Junction plate } \\
\text { guideway's pitching } \\
\text { vibration }\end{array}$ \\
\hline
\end{tabular}

TABLE 3: The first-six-order natural frequencies of overall machine tool (unit: $\mathrm{Hz}$ ).

\begin{tabular}{lccc}
\hline Order & $\begin{array}{c}\text { FEM model } \\
\text { frequency }\end{array}$ & $\begin{array}{c}\text { Experimental } \\
\text { measured frequency }\end{array}$ & Error \\
\hline 1 & 27.5 & 25.8 & $6.6 \%$ \\
2 & 53.7 & 50.3 & $6.8 \%$ \\
3 & 55.1 & 55.9 & $1.4 \%$ \\
4 & 78.7 & 68.0 & $14.7 \%$ \\
5 & 83.0 & 85.6 & $3.0 \%$ \\
6 & 115.7 & 107.9 & $7.2 \%$ \\
\hline
\end{tabular}

the process exerted by the dynamic property of the machining center, the acceleration sensor is attached to the bottom of the principal axis and the vibration signal is collected. Respectively, knock on eight main components, which are the column, longeron, sliding plate, crossbeam, sliding box, ram, spindle box, and the bottom of the principal axis. Test the natural frequency of the overall machine and compare the results with frequency obtained from FEM analysis. The results are shown in Table 3. The method to calculate the error is shown as follows.

Relative Error

$$
=\frac{\text { Computed Value }- \text { Measured Value }}{\text { Measured Value }} \times 100 \% \text {. }
$$

The result of the experiment indicates that the solution of the FEM analysis has a relative small error compared to the experimental result, and the simulation of FEM model well matches the practical situation.

\section{Conclusion}

Based on the research of static property of the linear rolling guideway, this paper makes a research on the dynamic performance of the rolling guideway and the simplified model of the guideway and the identification of dynamic parameters. At the same time, the research achievement is applied to a gantry machining center driven by a linear electric motor, which solves the problem of dynamic modeling of contact interface in NC machine tool. On account of the research mentioned above, the conclusions are obtained as follows.

(1) Based on the Hertz contact theory, the relation between the bearing load and deformation of the linear rolling guideway is detected to be approximate linear function. In the simplified model it can be replaced by the linear model.

(2) Based on the Lagrange method, we conduct a research on the vibration property of the linear guideway and deduce the dynamic equations. It is explained through model analysis that the 'Slider-Roller-Guideway' system has multiple vibration modes called pitching vibration, yawing vibration, vertical vibration, low order rolling vibration, and high order rolling vibration, which means that it is a complex multiple modes system. Therefore, we use the multigroups of vertical and horizontal "spring-damper" system as the simplified equivalent model.

(3) The paper proposed a type of guideway contact interface modeling method combining four stages which were static stiffness model, vibration model, experimental parameter, and parameter identification. This method is effective while solving the stiffness and damping value of the guideway equivalent model. Moreover, it solves the key problem in machine tool modeling-the problem of contact interface modeling.

(4) Combined with the research and development of the practical machine tool, for the object of a type of gantry machining center, we establish an overall FEM model of the gantry machining center driven by linear motors which includes the guideway contact interface model; moreover, the results of natural frequencies and modes of the machine tool are obtained. By comparing the computed solution with the experimental result, the efficiency and accuracy of the guideway contact interface model is verified.

(5) The spring model is used to replace the roller in the guideway system to improve the comprehension of stiffness and damping in the joint. However, when the interaction in the joint is needed to consider, the spring model is not suitable for simplified modeling of the roller, and it will be discussed in the future research. 


\section{Competing Interests}

The authors declare that they have no competing interests.

\section{Acknowledgments}

This study was supported by the National Science Foundation of China (Grant no. 61403010).

\section{References}

[1] S. Wen, X. Zhang, and M. Wu, "Fractal model and simulation of normal contact stiffness of joint interfaces and its simulation," Transactions of the Chinese Society for Agricultural Machinery, vol. 40, no. 11, pp. 197-202, 2009.

[2] S. Wen, X. Zhang, X. Wen, P. Wang, and M. Wu, "Fractal model of tangential contact stiffness of joint interfaces and its simulation," Transactions of the Chinese Society of Agricultural Machinery, vol. 40, no. 12, pp. 223-227, 2009.

[3] G. Zhang, W. Shi, and Y. Huang, "Analysis method of dynamic behavior of guideway joint and its application in machine tools design," Jixie Gongcheng Xuebao/Chinese Journal of Mechanical Engineering, vol. 38, no. 10, pp. 114-117, 2002.

[4] K. Mao, B. Li, and B. Xie, "Rolling linear guide pair movable joint dynamic modeling," Journal of Huazhong University of Science and Technology (Natural Sciences), vol. 36, no. 8, pp. 8588, 2008.

[5] J. S. Dhupia, B. Powalka, A. Galip Ulsoy, and R. Katz, "Effect of a nonlinear joint on the dynamic performance of a machine tool," Journal of Manufacturing Science and Engineering, Transactions of the ASME, vol. 129, no. 5, pp. 943-950, 2007.

[6] Y. Zhang and B. Liao, "Effective parameter identification method of joint part of machine tool," Journal of Kunming University of Science and Technology, vol. 23, no. 2, pp. 36-41, 1998.

[7] S. S. Park, Y. Altintas, and M. Movahhedy, "Receptance coupling for end mills," International Journal of Machine Tools and Manufacture, vol. 43, no. 9, pp. 889-896, 2003.

[8] X. Zhang, Y. Tang, and Y. Xu, "Identification method of the stiffness of contact interface by using experimental modality and FEM method," Modular Machine Tool \& Automatic Manufacturing Technique, vol. 11, pp. 56-60, 2005.

[9] H. Ohta and E. Hayashi, "Vibration of linear guideway type recirculating linear ball bearings," Journal of Sound and Vibration, vol. 235, no. 5, pp. 847-861, 2000.

[10] J. S. Wu, J. C. Chang, and J. P. Hung, "The effect of contact interface on dynamic characteristics of composite structures," Mathematics and Computers in Simulation, vol. 7, no. 3, pp. 114, 2006.

[11] J. Zheng, J. Zhang, and Q. Sun, "Parameter identification based on modal theory of slider contact interface of spherical guide way of machine tool," Precise Manufacturing \& Automation, vol. 3, pp. 19-20, 2005.

[12] D. Xu, Q. Liu, and S. Yuan, "Research on static stiffness of linear rolling guide way," Machine Tool \& Hydraulics, vol. 36, no. 4, pp. 8-10, 2008. 


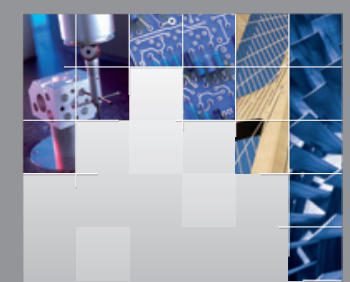

\section{Enfincering}
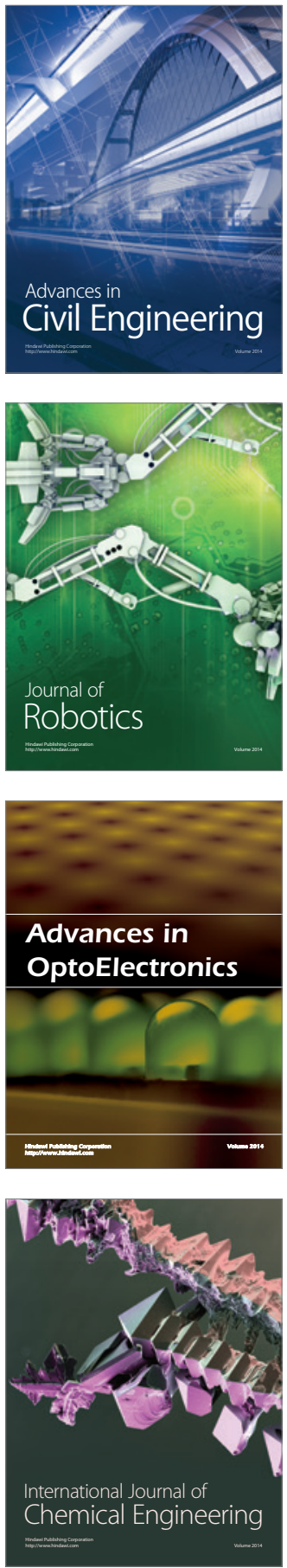

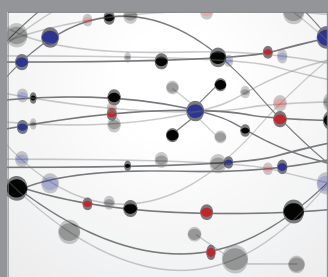

The Scientific World Journal

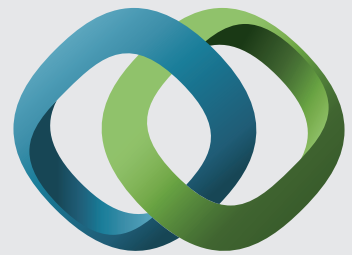

\section{Hindawi}

Submit your manuscripts at

http://www.hindawi.com
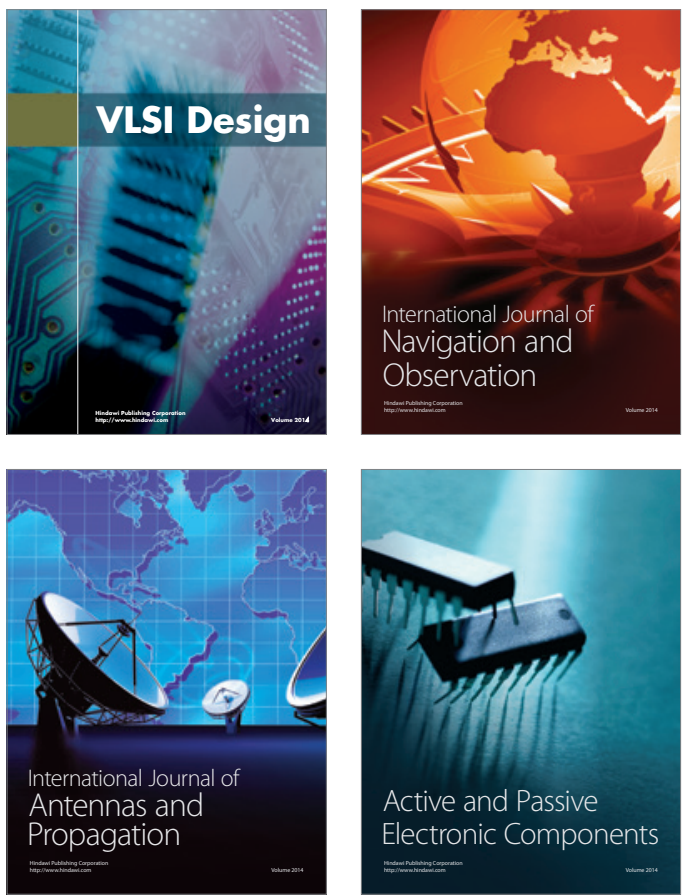
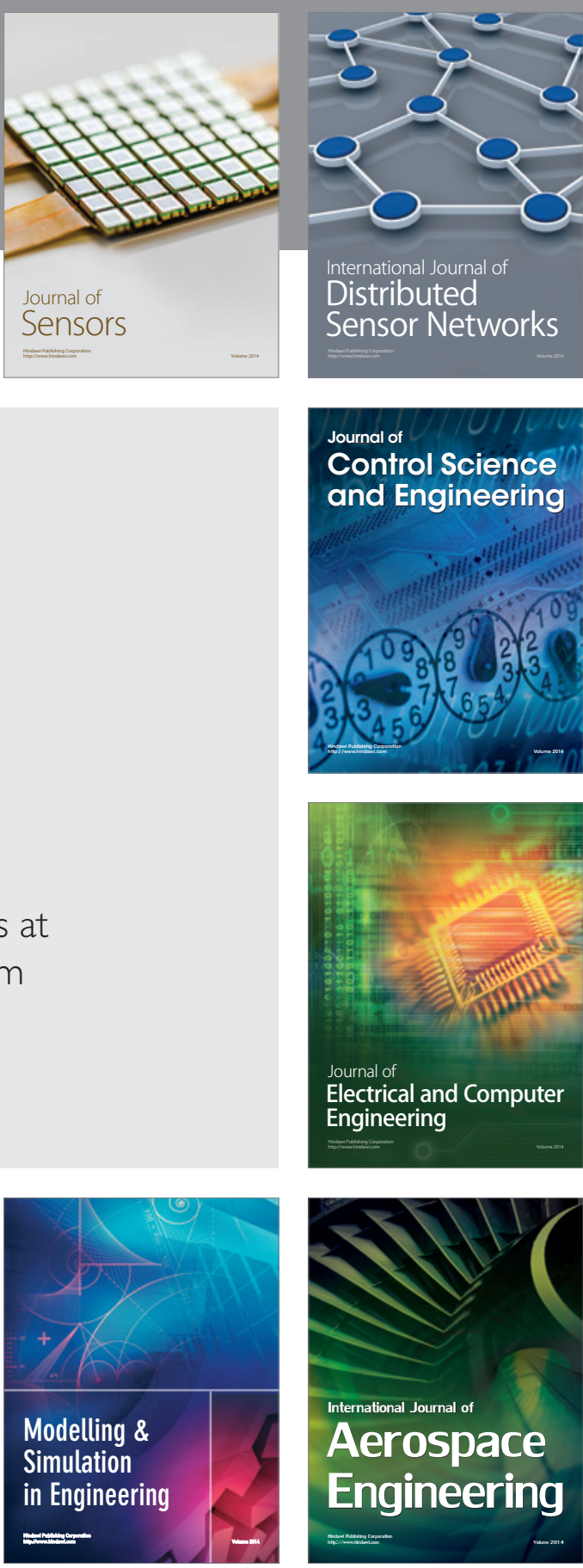

International Journal of

Distributed

Sensor Networks

Journal of

Control Science

and Engineering
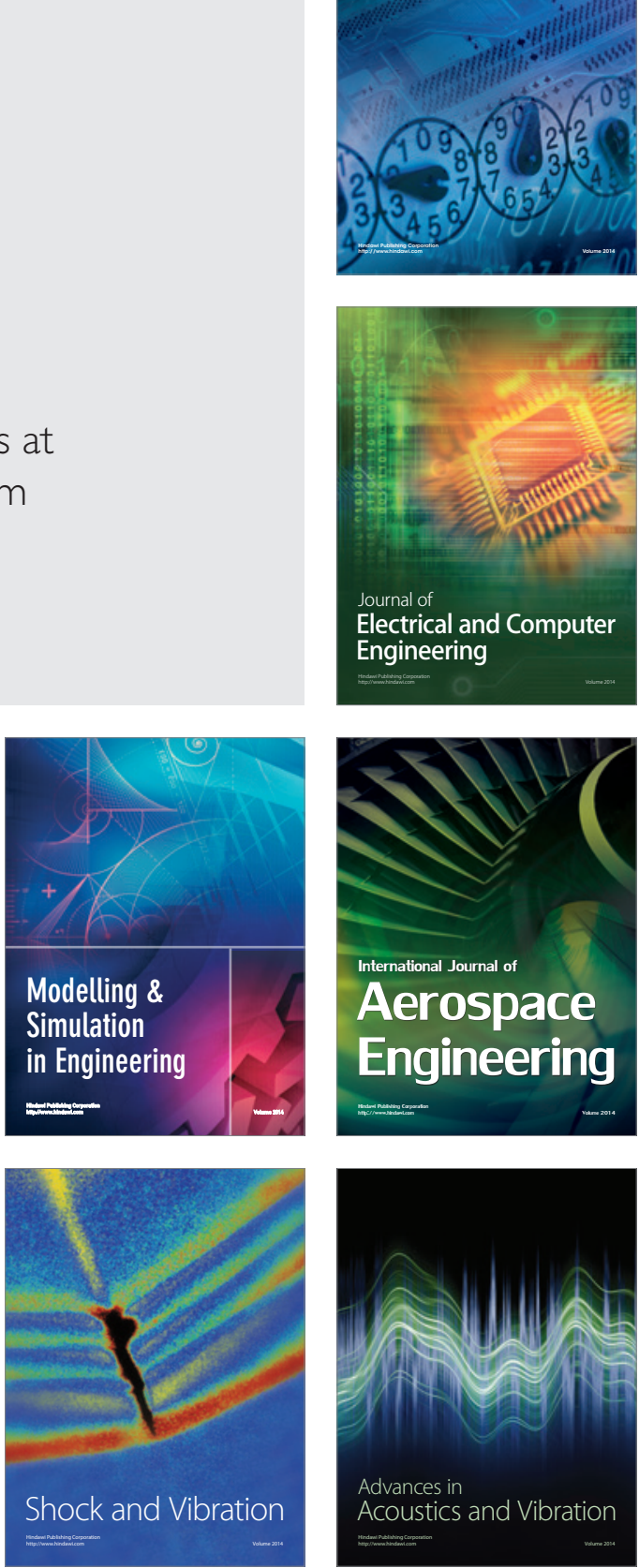